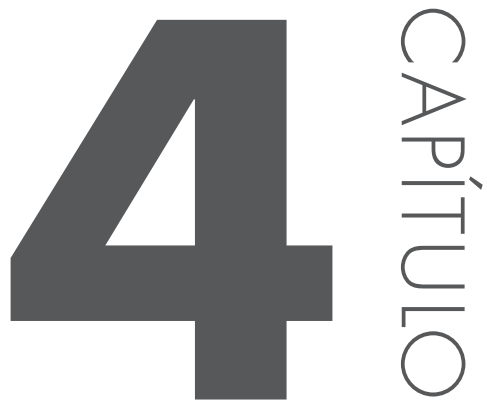

\title{
PROCESSOS DE BIOCONVERSÃO APLICADOS À OBTENÇÃO DE FÁRMACOS E INTERMEDIÁRIOS
}

Maria Antonieta Ferrara

Antonio Carlos Siani

Elba Pinto da Silva Bon

\subsection{INTRODUC̣ÃO}

No curso da história da civilização, o homem descobriu que os micro- organismos poderiam ser seus aliados na transformação e adaptação de substratos orgânicos às suas necessidades cotidianas. Assim, mesmo antes de ter qualquer noção da existência deles, o homem já os usava para a produção de alimento e bebidas. Pode-se afirmar o mesmo para as enzimas, que, paralelamente, tiveram aplicações similares com base empírica, como bem exemplifica o uso do suco gástrico de bezerros na manufatura de queijos, um procedimento cuja origem é indeterminada no tempo. Esse processo de modificar certos compostos por reações simples e bem definidas quimicamente, catalisadas por micro-organismos ou por enzimas isoladas é, nos dias de hoje, denominado "biotransformação" ou "bioconversão" 1 . 
Assim, a bioconversão subentende os processos que utilizam enzimas isoladas, micro-organismos ou células de plantas para converter uma molécula precursora, em geral um xenobiótico, em um produto de alto valor agregado. A diferença essencial entre fermentação e biotransformação é que a fermentação ocorre a partir de fontes de nutrientes e de energia e envolve inúmeras etapas catalíticas entre o substrato e o produto gerado, enquanto há apenas um ou poucos passos reacionais em uma biotransformação. Adicionalmente, as estruturas químicas do substrato e do produto são similares ou aparentadas, o que não necessariamente ocorre na fermentação. Neste processo, a molécula que sofrerá a transformação é adicionada ao sistema biológico já constituído, e o produto normalmente envolve uma substância com valor agregado que justifique a utilização da conversão biológica (Figura 4.1) $)^{1}$.

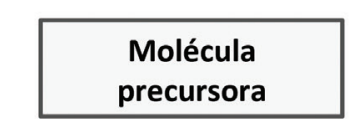

Produto natural ou de síntese (xenobiótico)

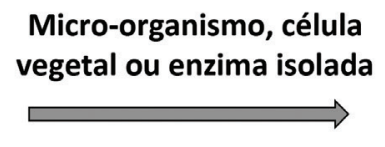

Maior atividade biológica, menor toxicidade etc.
Produto de alto valor agregado

Figura 4.1 Representação esquemática do processo de bioconversão.

As enzimas são biocatalisadores eficientes, cujo potencial de suporte a processos tecnológicos é evidenciado pela diversidade existente dessas moléculas e, por extensão, pela variedade e complexidade de reações químicas que podem ser catalisadas enzimaticamente. Nesse contexto, a International Union of Biochemistry and Molecular Biology (IUBMB) reconhece mais de 5.858 diferentes enzimas (dados de novembro de 2016), que estão catalogadas em seu site". Essa homepage é um repositório de informações e descreve cada tipo de enzima caracterizada, com a sua identificação segundo a Enzyme Commission (EC). A Tabela 4.1 apresenta as seis classes de enzimas e o tipo de reação catalisada. Cada classe é dividida em mais três subclasses

* Ver www.expasy.ch/enzyme. 
progressivas, que classificam as enzimas de forma mais específica. A Figura 4.2 exemplifica essa divisão para a classe das oxidorredutases.

Em contrapartida aos catalisadores químicos tradicionais, as enzimas apresentam elevada especificidade nas alterações que promovem nos substratos. Assim, os processos de bioconversão normalmente geram produtos com químio, régio e enantiosseletividade, minimizando ou mesmo eliminando a formação de subprodutos, com ganhos de rendimento no produto de interesse e, por conseguinte, com considerável diminuição de custos com as etapas de separação e purificação. Essa vantagem inclui a utilização de condições reacionais brandas e o envolvimento de menos etapas reacionais. Também evita a necessidade de proteger grupos químicos lábeis e exime o emprego de solventes orgânicos para a reação, resultando em menor consumo de energia, menor impacto ambiental dos efluentes gerados nos processos enzimáticos (ressaltando-se a inerente biodegradabilidade das próprias enzimas) e não acumulação de resíduos no meio ambiente (ao contrário do que ocorre com os catalisadores químicos, muitas vezes poluentes e de difícil degradação). Além disso, as enzimas e os micro-organismoss oferecem a opção de serem imobilizados para reúso em ciclos, possibilitando conduzir processos contínuos de biotransformação ${ }^{1-5}$.

Tabela 4.1 Classes das enzimas e tipo de reação catalisada

\begin{tabular}{|c|c|c|}
\hline EC & NOME & TIPO DE REAÇÃO CATALISADA \\
\hline 1 & Oxidorredutases & Oxidação/redução, Oxigenaçã̃o de ligações $C-H, C-C, C=C, C=0$ ou adição/abstração de prótons \\
\hline 2 & Transferases & $\begin{array}{l}\text { Transferências de grupos funcionais: aldeído-, cetona-, acil-, } \\
\text { glicosil-, grupos contendo fósforo, entre outras }\end{array}$ \\
\hline 3 & Hidrolases & Hidrólise/formação de ésteres, amidas, epóxidos, nitrilas, anidridos \\
\hline 4 & Liases & Adição/eliminação de pequenas moléculas em ligações $C=C, C=N, C=0$ \\
\hline 5 & Isomerases & Isomerisaçães (racemizaç̦ão, epimerizaç̦ão) \\
\hline 6 & Ligases & Formaç̃ão/quebra de ligaç̃oes C-O, C-S, C-N, C-C com consumo de ATP \\
\hline
\end{tabular}

Da perspectiva tecnológica, a vantagem mais explícita da bioconversão é sua capacidade inerente de realizar transformações químicas que seriam inviáveis ou economicamente desvantajosas pela via da síntese orgânica. Em seguida, porém não menos importante, está a enantiosseletividade dos processos biocatalisados ${ }^{1,6,7}$. Dada sua relevância, essa característica tem impulsionado sobremaneira o emprego da tecnologia biocatalítica em processos 


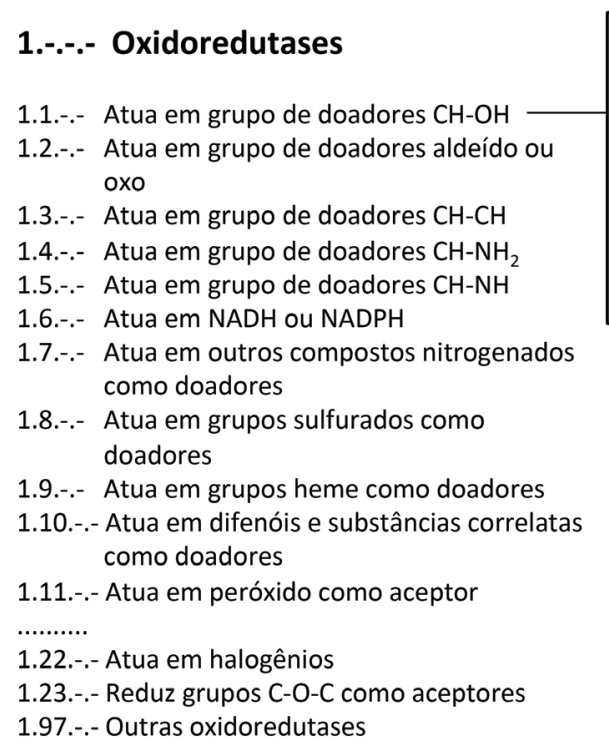

1.1.1.- com NAD(+) ou NADP(+)como aceptor

1.1.2.- com citocromo como aceptor

1.1.3.- com oxigênio como aceptor

1.1.4.- com dissulfeto como aceptor

1.1.5.- com quinona ou compostos semelhantes como aceptor

1.1.9.- com proteína com cobre como aceptor

1.1.98.- com outros aceptores conhecidos

1.1.99.- com outros aceptores

\begin{tabular}{|c|c|}
\hline 1.1.1.1 & alcooldesidrogenase \\
\hline 1.1.1.2 & alcooldesidrogenase $(\mathrm{NADP}(+))$ \\
\hline 1.1.1.3 & homoserinadesidrogenase \\
\hline 1.1.1.4 & $(\mathrm{R}, \mathrm{R})$-butanodioldesidrogenase \\
\hline 1.1.1.5 & $\begin{array}{l}\text { transferido para EC 1.1.1.303 e EC } \\
\text { 1.1.1.304 }\end{array}$ \\
\hline 1.1.1.6 & gliceroldesidrogenase \\
\hline 1.1.1.7 & propanodiol-fosfatodesidrogenase \\
\hline \multicolumn{2}{|l|}{........... } \\
\hline \multicolumn{2}{|c|}{ 1.1.1.365 D-galacturonato redutase } \\
\hline \multicolumn{2}{|c|}{ 1.1.1.366 L-idonato 5-desidrogenase (NAD $\left.{ }^{+}\right)$} \\
\hline
\end{tabular}

Figura 4.2 Diversidade das enzimas, exemplificada pelas subclasses das oxidoredutases.

desenvolvidos para vários setores industriais, em especial o de fármacos ${ }^{8-10}$. Um exemplo desse fato é um levantamento realizado em 2006 que evidencia os fármacos e intermediários de drogas como os produtos mais importantes obtidos por biotransformação, já à época representando mais de $50 \%$ dos processos implantados industrialmente ${ }^{11}$. Entre os princípios ativos constituídos de moléculas pequenas, aprovados para uso pela agência norte-americana Food and Drug Administration (FDA) em 2006, 80\% eram compostos quirais e $75 \%$ eram enantiômeros puros ${ }^{8}$.

A produção seletiva de um único enantiômero é uma característica buscada para inúmeras moléculas de fármacos, que pode ser viabilizada pelo uso de biocatalisadores. Nesse contexto, além de permitir a redução das etapas (em comparação com a síntese química), a economia em precursores caros e a redução dos custos com purificação são fatores altamente atrativos nos processos que dão suporte à produção em larga escala, principalmente na indústria de fármacos. A razão para tal é que, comumente, os enantiômeros de uma substância bioativa apresentam efeitos farmacológicos e tóxicos diferentes, podendo ser ambos benéficos (atividade sobre o alvo terapêutico) ou um deles benéfico e o outro indesejado (tóxico, inibidor ou inativo). 
Um exemplo emblemático é a talidomida, cuja forma dextrógira (enantiômero R) apresenta efeito sedativo, enquanto a forma levogira (enantiômero S) é teratogênica. A propriedade desta segunda forma levou à retirada do mercado da talidomida racêmica, após se descobrir seu efeito causador da deformidade em fetos. Entre seu lançamento em 1957, indicada para controlar enjoos, e a proscrição do mercado em 1962, seus efeitos nefastos provocaram uma mudança de paradigma no desenvolvimento de drogas. A partir daí, a regulamentação da indústria farmacêutica aumentou o grau de exigência em relação aos princípios ativos, de forma a garantir que o produto final contenha apenas o enantiômero eficaz de um medicamento. Das dez principais drogas existentes no mercado em 2004, seis eram constituídas de enantiômeros puros, duas de misturas racêmicas, duas de compostos não quirais e uma de proteína recombinante ${ }^{8}$. A Figura 4.3 ilustra a importância da utilização do enantiômero correto em moléculas bioativas.

Uma vez que produzem a mistura racêmica, os processos sintéticos tradicionais normalmente lançam mão de duas estratégias para obter apenas um dos enantiômeros. Uma delas inclui iniciar o processo com materiais já oticamente puros, utilizando processos que não afetem a quiralidade do material de partida. A outra envolve a aplicação de técnicas de síntese assimétrica que favoreçam o curso das reações para a obtenção do enantiômero desejado. Todavia, tanto a síntese de misturas racêmicas ou mesmo os processos com determinados graus de estereoespecificidade exigem a posterior aplicação de algum método de resolução quiral para separar os enantiômeros. Esta tarefa é dificultada devido às propriedades físicas e químicas de ambos os enantiômeros serem virtualmente idênticas (à exceção do comportamento frente à luz polarizada). Ambas essas abordagens para produzir apenas um dos enantiômeros embutem uma relação de custo-benefício econômico bastante desfavorável. Além disso, essa questão é uma condição existente para todos os fármacos que possuem centros quirais.

O uso de processos de biotransformação é atualmente considerado uma vantagem que impacta diretamente a competitividade industrial devido aos seus benefícios econômicos, já que incluem menores custos de processo, maior qualidade do produto final e obtenção de produtos inteiramente novos, em comparação aos processos sintéticos. Adicionalmente, os processos com base em biotransformação têm sido considerados pela sua contribuição na implementação dos chamados processos verdes, que se destacam por resultarem em ganhos evidentes, como menor consumo de energia e preservação ambiental $1^{1,9,10}$. 
<smiles>O=C1CCC(N2C(=O)c3ccccc3C2=O)C(=O)N1</smiles>

(R)-Talidomida sedativa<smiles>CC[C@H](CO)NCCN[C@H](CC)CO</smiles>

Etambutol - isômero (S,S) tuberculostático<smiles>O=C(N[C@H](CO)[C@H](O)c1ccc([N+](=O)[O-])cc1)C(Cl)Cl</smiles>

Cloranfenicol - isômero (R,R) antibiótico<smiles>O=C1CC[C@H](N2C(=O)c3ccccc3C2=O)C(=O)N1</smiles>

(S)-Talidomida teratogênica<smiles>CC[C@H](CO)NCCN[C@H](CC)CO</smiles>

Etambutol - isômero $(\mathrm{R}, \mathrm{R})$ causa cegueira<smiles>O=C(N[C@H](CO)[C@@H](O)c1ccc([N+](=O)[O-])cc1)C(Cl)Cl</smiles>

Figura 4.3 Exemplos da importância da abordagem quiral em fármacos.

Por esse motivo, os processos de bioconversão vêm rapidamente adquirindo relevância dentro da academia científica e no setor industrial, já que a pauta atual do desenvolvimento sustentável pressupõe o aumento paulatino do emprego de matérias-primas renováveis e de processos com tecnologias limpas. Assim, o desenvolvimento tecnológico com base na bioconversão vem ganhando espaço em setores produtivos diversos, como o de alimentos, produtos para a agroindústria, cosméticos e, em especial, fármacos e medicamentos $^{11,12}$.

\subsection{HISTÓRICO}

Desde remota antiguidade, os micro-organismos têm tido uma enorme importância social e econômica na vida do ser humano, como atestam alguns 
registros arqueológicos e históricos. Em cerca de 6000 a.C., os sumérios e babilônios já preparavam a cerveja e os egípcios já utilizavam leveduras para fazer pão, além da preparação do vinho já estar mencionada no Pentateuco (Gênesis). Uma prática que remonta a 2000 a.C., e através dos tempos estabeleceu-se como o paradigma mais patente da transformação realizada com a mediação de células vivas, é a preparação do vinagre. Esse remoto exemplo de oxidação microbiana serve ainda hoje para ilustrar importantes desenvolvimentos que ocorreram no campo da bioconversão, haja vista que o produto dessa transformação, quando obtido por bactérias que processam o etanol para ácido acético, ainda hoje é chamada de vinagre (Figura 4.4).

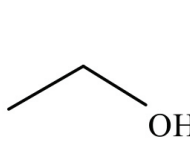

etanol

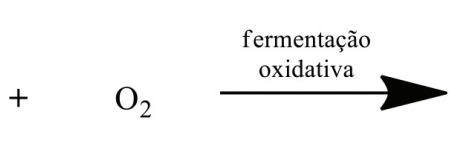

oxigênio

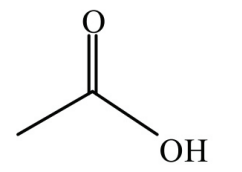

ácido acético
$+\mathrm{H}_{2} \mathrm{O}$

água

Figura 4.4 Bioconversão de etanol em ácido acético (preparação do vinagre).

As primeiras comunicações sobre a bioquímica dos processos fermentativos envolvendo álcoois e ácidos orgânicos surgiram na segunda metade do século XIX. Vale ressaltar, todavia, que estas só ocorreram depois que R. Hooke, no final do século XVII, ao utilizar o microscópio recém-desenvolvido pelo holandês A. Von Leeuwenhoek, demonstrou serem os seres vivos compostos de pequenas unidades básicas, então denominadas células. Esse foi um marco na biologia experimental, e pode ser também considerado como o ponto de partida no desenvolvimento da bioconversão, já que deu suporte à descoberta das leveduras por L. Pasteur ${ }^{13}$. É interessante o fato de a pesquisa sobre fermentações, à época, estar relacionada a uma preocupação com as moléculas oticamente ativas. Em 1858, Pasteur divulgou o sucesso obtido na resolução ótica do ácido tartárico por via microbiana, ao realizar a fermentação do sal de amônio do ácido racêmico mediada por Penicilium glaucum ${ }^{14}$. Nesse processo, o fungo metabolizava e degradava apenas o ácido levógiro (+)-tartárico, deixando intacto o ácido dextrógiro (-)-tartárico, que então era purificado por cristalização. Em 1862, Pasteur também investigou a conversão do álcool em vinagre e propôs que 
o mecanismo de transporte de oxigênio do ar para o substrato em solução ocorria através de uma película que se formava durante o processo ${ }^{15}$. Isso foi confirmado anos mais tarde, em 1886, pelo químico A. J. Brown, que denominou o agente contido nessa película de Bacterium xylinum, demonstrando

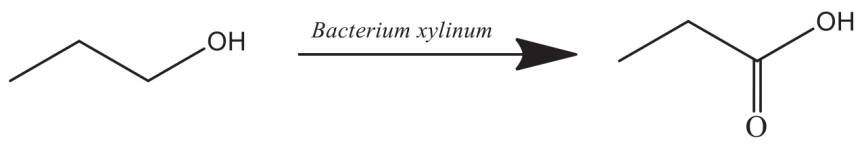

propan-1-ol

ácido propiônico

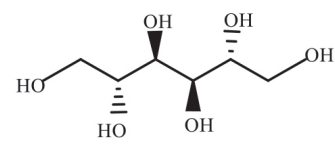

manitol
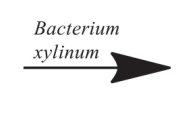

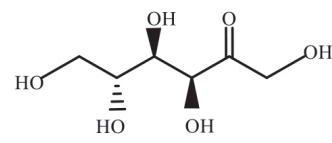

frutose

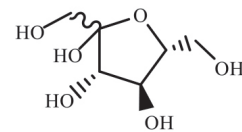

$\mathrm{OH}$

-

Figura 4.5 Bioconversões do propano-7-ol em ácido propiônico e de manitol em frutose (figura elaborada com base em Vasic-Racki, $2006^{13}$ e Sebek, 1982 16 ).

também a capacidade deste de transformar propanol para ácido propiônico e manitol para frutose (Figura 4.5 ${ }^{16}$.

Naquela época, investigações paralelas sobre o uso de enzimas também prosseguiam de maneira promissora. As enzimas também possuíam um histórico de milhares de anos de utilização pelo homem, antes de serem inteiramente compreendidas em sua natureza. O exemplo mais emblemático é o emprego do suco gástrico de bezerros na manufatura de queijos, um procedimento cuja origem, como já dissemos, é indeterminada no tempo. Em 1783, L. Spallanzani demonstrou que o suco gástrico digeria carne, devido à presença do que T. Schawn, em 1836, chamou de pepsina ${ }^{17}$. Três anos antes, o francês A. Payen isolou um complexo enzimático do malte que era capaz de digerir o amido, produzindo glicose, o qual chamou de "diastase"13.

Em 1897, E. Buchner conseguiu fermentar a glicose para etanol e gás carbônico com levedura inativada, ao esmagar as células pela fricção com $\operatorname{areia}^{18}$. Essa descoberta convergiu com as pesquisas, já na época, realizadas com enzimas, e resultou numa diferenciação entre o que se passou a chamar de "fermentos organizados", produzidos por extratos de células fermentativas (como o caso de Buchner); e "fermentos não organizados", como as 
secreções celulares do tipo suco gástrico. Hoje, esses termos representam, respectivamente, as enzimas "intracelulares" e "extracelulares". O experimento pioneiro de Buchner evidenciou que o potencial de promover transformações químicas estaria ligado, em última instância, ao conteúdo celular - excretado ou não - dos organismos vivos. O termo "enzima” já havia sido proposto por W. F. Kühne em um artigo de 1876 sobre a tripsina pancreática, para denominar então os fermentos "não organizados"13.

Dentro de seu monumental legado sobre a química dos açúcares, H. M. Fisher observou, em 1894, que a enzima conhecida como emulsina catalisava a hidrólise do $\beta$-metil-(D)-glicosídeo, enquanto a enzima conhecida como maltase era ativa sobre o $\alpha$-metil-(D)-glicosídeo ${ }^{19,20}$ (Figura 4.6). Esse
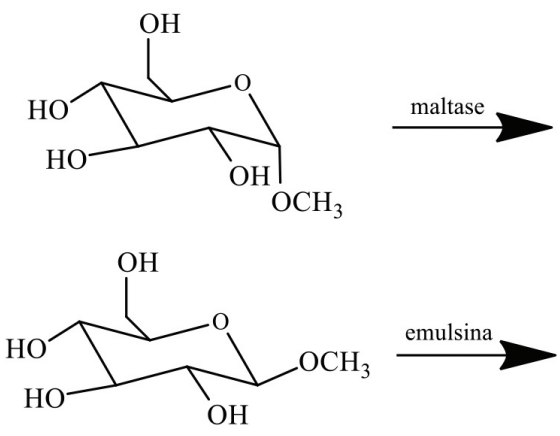
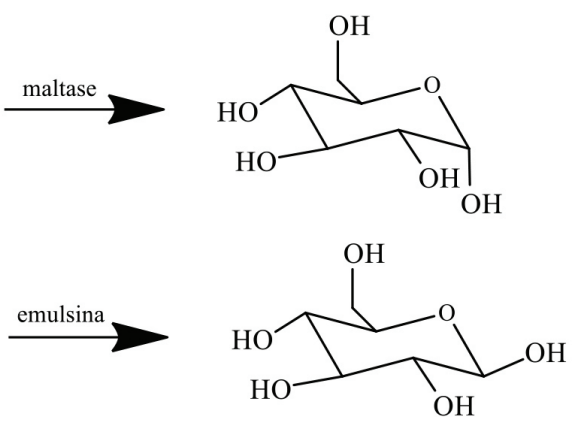

Figura 4.6 Experimentos de Fisher que embasaram a teoria "fechadura e chave" para a ação enzimática (figura elaborada com base em Vasic-Racki, $2006^{13}$ ).

evento levou-o a sugerir a famosa teoria da "fechadura e chave" para definir a especificidade enzimática.

O estudo da cinética da catálise enzimática teve um marco importante com a equação desenvolvida em 1913 por L. Michaelis M. L. Menten, que trabalharam com a ação de enzimas purificadas sobre substratos simples (sacarose). A velocidade da reação de conversão enzimática seria dependente da formação de um intermediário na forma de complexo enzima-substrato ${ }^{21}$. Posteriormente, a equação foi generalizada por outros pesquisadores ${ }^{22}$.

A década de 1920 marcou uma nova etapa no estudo da cinética enzimática, iniciada com os estudos da tripsina purificada, por J. A. V. Butler ${ }^{13,23}$; assim como a cristalização da primeira enzima de origem vegetal, a urease, extraída da Canavalia ensiformis (feijão-de-porco) por J. B. Sumner ${ }^{24}$, o qual 
também primeiro enunciou as enzimas como sendo proteínas. No final da década de 1940, muitas enzimas estavam disponíveis na forma purificada por cristalização. A primeira enzima a ser sintetizada em laboratório foi a ribonuclease A, em 1969, por R. Gutte e R. B. Merrifield, que utilizaram métodos em fase sólida ${ }^{25}$. Um ano depois, as estruturas moleculares de diversas enzimas foram estabelecidas, o que permitiu avançar nos estudos de mecanismos de ação.

Ainda com fundamento empírico, a utilização escalonada de micro-organismos e de enzimas para obtenção de produtos com valor comercial estabeleceu-se antes mesmo de haver uma compreensão científica mais completa da natureza e do comportamento desses agentes biológicos aplicados a conversões químicas. O protótipo do primeiro biorreator já teria sido construído na França em 1823, com base na imobilização de bactérias para a produção de vinagre por fermentação oxidativa ${ }^{26-28}$. O primeiro exemplo de produção industrial com base em fermentação do qual se tem registro foi a do ácido láctico oticamente ativo, em 1880, nos Estados Unidos ${ }^{13,29}$.

A perspectiva de produção de moléculas com valor agregado pela via dos micro-organismos começou a se concretizar na década de 1920, a partir dos resultados de alguns experimentos que produziram moléculas então de alto interesse farmacêutico. Entre esses estavam: a obtenção estereoespecífica da 1-hidroxi-1-fenilpropan-2-ona pela condensação de duas moléculas distintas, promovida por Saccharomyces cerevisiae ${ }^{30}$; a oxidação controlada do D-sorbitol em L-sorbose ${ }^{31}$; e a conversão da progesterona em $11 \alpha$-hydroxiprogesterona pelo fungo parasita de frutos e vegetais maduros, o Rhizopuz arrhius, em presença de oxigênio ${ }^{32}$. A primeira dessas moléculas abriu caminho para a produção da efedrina, um dos mais antigos medicamentos para problemas do trato respiratório, pela empresa alemã Knoll AG, em $1930^{13}$. Na mesma época, a empresa Reichstein-Grüssner A estabeleceu um processo para obter a L-sorbose, este um intermediário-chave no processo de produção da vitamina $\mathrm{C}$ (ácido ascórbico) ${ }^{13}$. A progesterona hidroxilada esteroespecificamente na posição C-11 pela via microbiana representou uma economia considerável na obtenção desse intermediário-chave na síntese do anti-inflamatório cortisona ${ }^{33}$. Esses três exemplos estão sintetizados na Figura 4.7.

Quanto à utilização de enzimas para proceder a conversões químicas, é digno de nota o fato de que, mesmo antes das evidências obtidas por Buchner, a comercialização de uma enzima extracelular alcançou o aumento de escala e a comercialização, por volta de 1890, graças ao empreendedor japonês Takamine, radicado nos Estados Unidos. Seu produto era uma mistura 


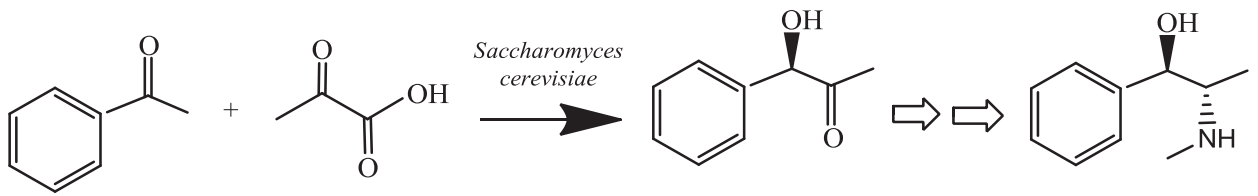<smiles>OC[C@@H](O)[C@@H](O)[C@H](O)[C@H](O)CO</smiles>

D-sorbitol

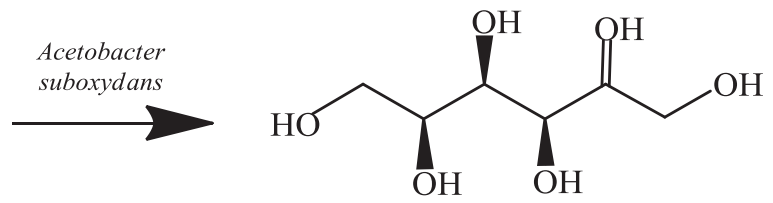

L-sorbose

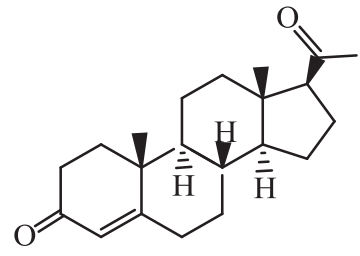

progesterona

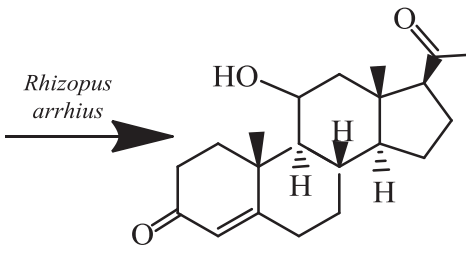

11-hidroxi-progesterona

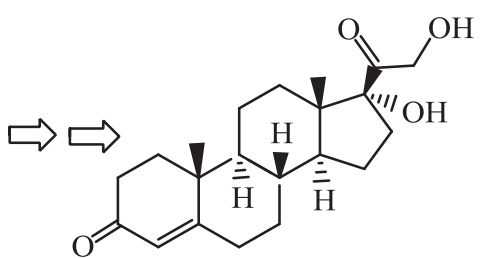

cortisona

Figura 4.7 Biotransformações que deram suporte aos primeiros processos industriais do século XX (figura elaborada com base em Vasic-Racki, $2006^{13}$ ).

de enzimas amilolíticas e proteolíticas de Aspergillus oryzae - que ele denominou takadiastase ${ }^{13}$.

Se a década de 1920 assistiu à bioconversão industrial por células íntegras, os processos de conversão enzimática em larga escala seriam expandidos exponencialmente depois da metade do século XX, com o estabelecimento das ferramentas de recombinação genética.

Os quadros das figuras 4.8 e 4.9 sumarizam os eventos históricos relevantes no desenvolvimento dos processos de bioconversão, ao demarcar as pesquisas realizadas com micro-organismos e com enzimas isoladas, respectivamente. 


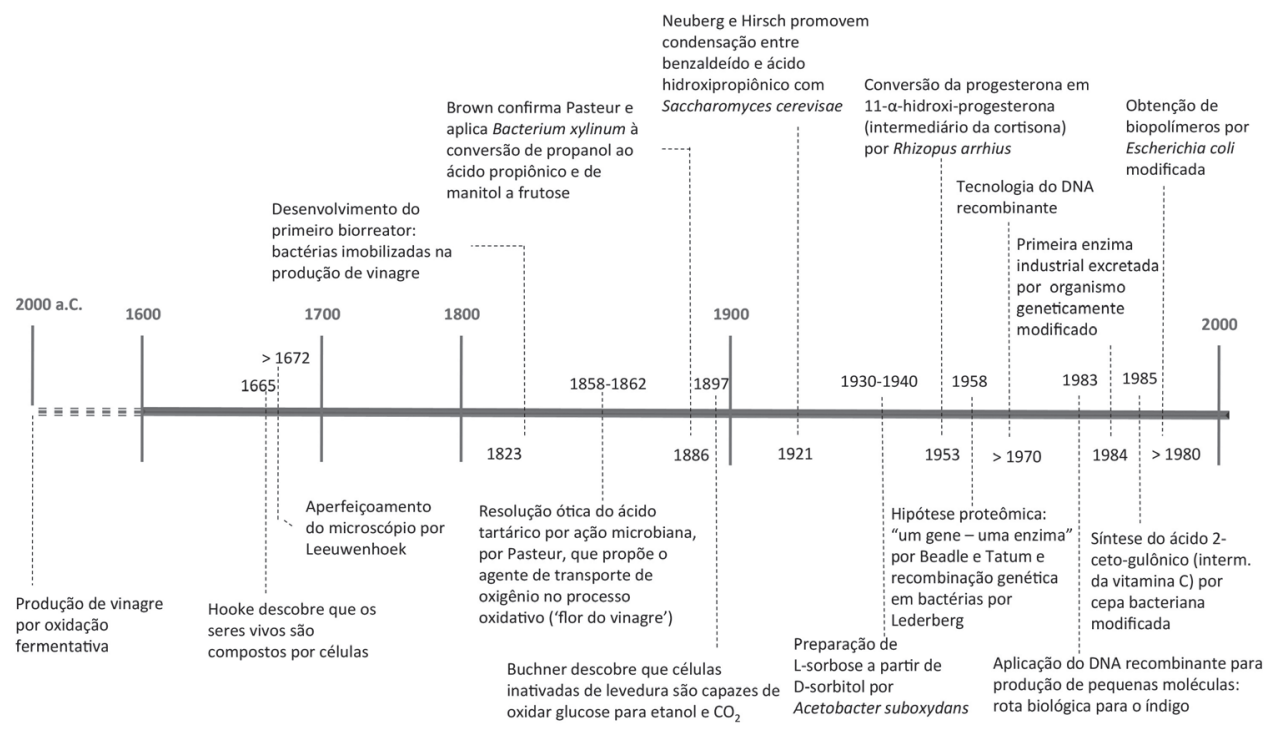

Figura 4.8 Marcos no desenvolvimento tecnológico da bioconversão utilizando micro-organismos. Figura elaborada com base em Vasic-Racki, $2006^{13}$.

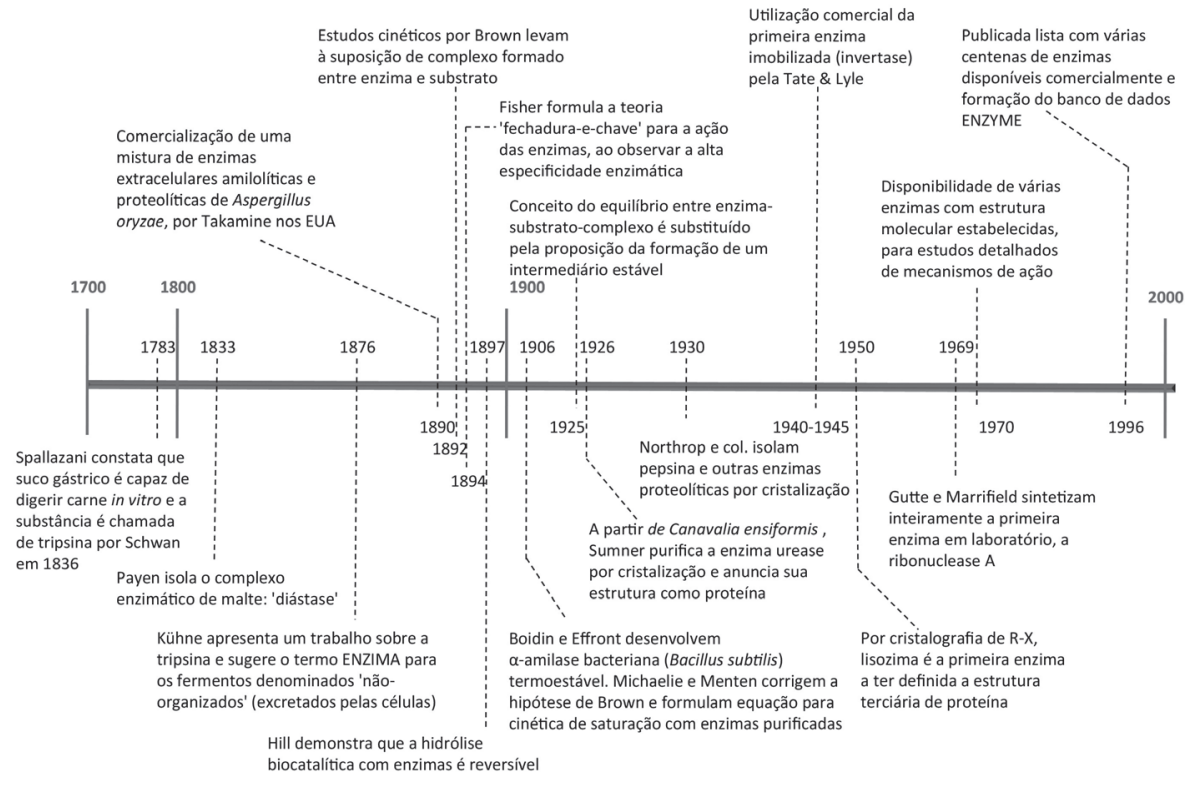

Figura 4.9 Marcos no desenvolvimento tecnológico da bioconversão utilizando enzimas. Figura elaborada com base em Vasic-Racki, $2006^{13}$. 


\subsection{FUNDAMENTOS DA BIOCONVERSÃO}

\subsubsection{Uso de células íntegras ou de enzimas isoladas}

Os processos de bioconversão podem utilizar células íntegras ou enzimas isoladas, podendo ambas estar na forma livre ou imobilizada. O uso de células íntegras para a bioconversão apresenta as seguintes vantagens ${ }^{2,5,9,34-37}$ :

- menor custo, por evitar as etapas de isolamento e purificação do biocatalisador;

- maior estabilidade do biocatalisador, pois o ambiente celular protege a enzima das condições reacionais externas, que podem ser prejudiciais para a sua estabilidade; a capacidade de regeneração de cofatores, essencial para reações de oxidorredução; e

- possibilidade de realização de reações sequenciais.

As principais desvantagens são:

- toxicidade de substratos e produtos, exigindo altas diluições;

- ocorrência de reações laterais, que podem causar a degradação do substrato ou do produto;

- excreção de metabólitos que podem dificultar a etapa de purificação; e

- maior dificuldade de controle e reprodutibilidade do processo.

Dependendo do sistema enzimático de interesse, as células a serem utilizadas nas reações de bioconversão podem estar viáveis ou não e ainda terem sido colhidas na fase de crescimento exponencial ou na fase estacionária. Isso porque existem diferenças no metabolismo das células e no padrão de expressão de genes que são peculiares para as diversas fases do ciclo celular. No caso de biotransformações envolvendo reações de oxidorredução, é necessário utilizar células viáveis, que são capazes de regenerar os cofatores. A realização dessas reações, de grande interesse na indústria química, exige a presença de uma fonte de elétrons, por exemplo, a glicose, ou de um receptor de elétrons, como o oxigênio ${ }^{2,11,12}$.

Por sua vez, as vantagens da utilização de enzimas isoladas são:

- requerimento de reatores mais simples; 
- etapas de purificação de produto mais simples; maior tolerância ao uso de solventes orgânicos; e

- minimização de problemas de contaminação com outras enzimas.

Já as desvantagens incluem:

- elevado custo das enzimas comerciais; e

- maior dificuldade de realização de reações sequenciais.

É importante mencionar que, para caso de reações de oxidorredução, existem estratégias para a regeneração de cofatores, conforme será abordado mais adiante.

\subsubsection{Estratégias para superar limitações dos processos de bioconversão}

À parte a disponibilidade e custo das enzimas, de forma geral, os processos de bioconversão apresentam limitações relacionadas à baixa solubilidade no meio aquoso (em que se localizam os sistemas biológicos) de grande parte dos substratos e produtos de interesse; a possibilidade de inibição da reação pelo substrato ou pelo produto; a instabilidade e falta de flexibilidade do biocatalisador; a baixa concentração do produto; os baixos rendimentos; e a baixa produtividade ${ }^{12}$.

Diversas estratégias podem ser empregadas para contornar essas limitações. A solubilidade aquosa de substratos, por exemplo, pode ser aumentada pela adição de detergentes (por exemplo, tween, entre outros) ou de solventes orgânicos imiscíveis com água (como metanol, etanol, acetona, isopropanol, dimetilformamida) ao meio reacional. Esses componentes, entretanto, devem ser cuidadosamente escolhidos de forma a não causarem toxicidade ou inibição ao biocatalisador. $\mathrm{O}$ uso de sistemas reacionais em duas fases, pelo emprego de solventes orgânicos apolares (por exemplo, tolueno, ciclohexano, éter metil-t-butílico), permite que substratos e produtos apolares sejam fornecidos ou retirados gradativamente do meio aquoso, diminuindo assim seus possíveis efeitos tóxicos ou inibidores ao biocatalisador. Além disso, o uso de duas fases permite separar de maneira relativamente fácil o catalisador, ao final do processo, uma vez que este permanece na fase aquosa, e reduzir o risco de contaminação microbiana. As desvantagens associadas a esse tipo de abordagem incluem: possibilidade de ação 
tóxica, inibitória ou desnaturante sobre o biocatalisador; maior complexidade do sistema operacional; possibilidade de formação de emulsão, que dificultaria a recuperação do produto; e maior dificuldade de tratamento dos efluentes ${ }^{1,12,38}$. A aplicação de sistemas de bioconversão na presença de solventes orgânicos é vasta, incluindo: síntese de peptídeos catalisada por proteases (quimiotripsina, termolisina ou tripsina); esterificação utilizando lipases; síntese de compostos quirais catalisada por lipases ou leveduras; desidrogenação de esteroides por desidrogenases ou células de bactéria, entre inúmeras outras ${ }^{38}$.

Os processos de bioconversão podem ainda ser favorecidos com a utilização dos chamados líquidos iônicos (LI), sais formados por cátions e ânions orgânicos ou inorgânicos líquidos a temperatura ambiente. Os LIs formam sistemas bifásicos com sistemas aquosos, fazendo o papel dos solventes orgânicos tradicionais e têm sido chamados de "solventes verdes" devido à baixa toxicidade e interessantes propriedades físicas e químicas, tais como a pressão de vapor desprezível, elevada estabilidade e baixo risco de explosão, o que possibilita a reciclagem do solvente no processo industrial ${ }^{39-41}$. Adicionalmente, os LIs podem ser modificados com relativa facilidade, de acordo com seus íons e suas cadeias laterais, gerando uma gama muito grande de possibilidades, já que suas propriedades físicas e químicas também variarão conforme as alterações moleculares ${ }^{41}$. Os processos de bioconversão de substâncias apolares catalisados por células em meio aquoso empregam geralmente LIs hidrofóbicos, como o hexafluorofosfato de 1-n-butil-3-metilimidazólio (BMI.PF ${ }_{6}$ ) e o bis-(trifluorometanosulfonil)imidato de butilimidazólio $\left(\text { BMI.NTf }_{2} \text { ) (Figura 4.10 }\right)^{42}$. Em que pese o custo ainda bastante

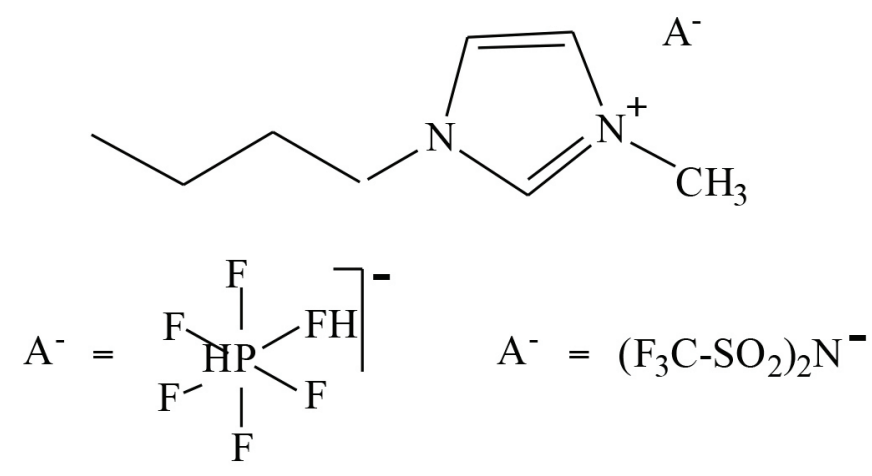

BMI.PF6

BMI.NTf2

Figura 4.10 Estrutras químicas dos líquidos iônicos BMI.PF e BMI.NTf. 
elevado dos LIs, seu uso em processos de bioconversão tem despertado um crescente interesse nos pesquisadores ${ }^{43-46}$.

Para o caso de substratos tóxicos ou que causem inibição ao sistema enzimático, utilizam-se também processos em batelada alimentada, no qual o substrato é adicionado gradativamente ao reator. Por seu lado, produtos deletérios podem ser removidos in situ através do uso, por exemplo, de resinas adsorventes ${ }^{47}$.

Outra ferramenta que tem se mostrado bastante útil em aplicações industriais por possibilitar o aumento da estabilidade do biocatalisador e facilitar a sua separação do meio reacional é a imobilização do catalisador. A imobilização de células ou enzimas pode ser efetuada através de ligação química covalente, adsorção ou interação iônica com um suporte inerte, como esferas de vidro, bem como através de encapsulação em matrizes ou incorparação em membranas, como ágar, K-carragenina, alginato, pectina ou poliacrilamida $^{1,43,48-51}$. Alguns aspectos importantes devem ser levados em conta, de forma que esse procedimento represente uma economia no custo global do processo; entre eles o custo da imobilização, a recuperação da atividade enzimática após imobilização do catalisador, a meia-vida operacional do biocatalisador imobilizado e os efeitos de transferência de massa ${ }^{9,48,49}$.

\subsubsection{Regeneração de cofatores em reações de oxidorredução com enzimas isoladas}

A regeneração de cofatores em processos de oxidorredução catalisados por enzimas isoladas é de extrema importância devido ao alto custo e baixa disponibilidade dos cofatores, que impedem o seu uso em quantidades estequiométricas. Diversos sistemas de regeneração de cofator foram desenvolvidos utilizando métodos químicos, eletroquímicos e fotoquímicos. No entanto, os métodos enzimáticos são os predominantes, devido a requisitos rigorosos de seletividade e compatibilidade com a reação de interesse.

A regeneração de cofatores por métodos enzimáticos pode ser efetuada pelo uso de sistemas com substratos acoplados, nos quais além do substrato que leva ao produto principal, emprega-se também um cossubstrato para regenerar o cofator; ou sistemas que contenham enzimas acopladas, nos quais a reação principal e a reação de reciclagem do cofator são catalisadas por enzimas diferentes.

No caso de sistemas com substratos acoplados, utiliza-se geralmente, como cossubstrato, um álcool secundário de baixo custo, como o isopropanol. O 
cossubstrato pode também atuar como um solvente do substrato principal, já que seu largo excesso colabora para deslocar o equilíbrio da reação no sentido desejado. Deve-se notar, entretanto, que a concentração do cossubstrato é limitada pela estabilidade da enzima na sua presença ou pela possibilidade de inibição da reação principal. A principal desvantagem desses sistemas é a sua baixa flexibilidade.

Os sistemas com enzimas acopladas apresentam como vantagem a maior flexibilidade da reação de reciclagem e a menor probabilidade de inibição da reação principal pelo cossubstrato e pelo coproduto. A reação de reciclagem deve preferencialmente proceder de maneira irreversível, para favorecer a termodinâmica do sistema. Assim, a velocidade da reação principal será a limitante do sistema.

Os critérios de escolha da reação de reciclagem incluem o uso de substratos e enzimas de baixo custo, a facilidade de remoção do coproduto (por exemplo, $\mathrm{CO}_{2}$ ), além da possibilidade de esse procedimento gerar um produto de interesse. De qualquer maneira, essa reação também não deve comprometer o rendimento ou a pureza ótica do produto da reação principal e o cossubstrato e o coproduto não devem dificultar o processo de recuperação do produto principal ${ }^{52-55}$.

\subsubsection{Etapas do desenvolvimento de um processo biocatalítico}

O desenvolvimento de um processo biocatalítico tem caráter essencialmente multidisciplinar. A capacidade de transformar, de forma eficiente e economicamente viável, uma molécula precursora em um produto de alto valor agregado envolve múltiplas etapas, as quais incluem a seleção, caracterização e otimização do biocatalisador (micro-organismos, célula vegetal ou enzima isolada), o desenvolvimento e otimização do bioprocesso em si e o desenvolvimento do processo de recuperação do produto (Figura 4.11).

A fonte primária de todas as enzimas é o código genético das células de micro-organismos, animais e plantas. Assim, muitas enzimas de uso industrial ainda são extraídas de tecidos animais e vegetais e, majoritariamente, são obtidas por fermentação microbiana. No caso de enzimas microbianas, a primeira etapa para obtê-las consiste na identificação do micro-organismo produtor. A linhagem de interesse pode ser adquirida de uma coleção de culturas ou selecionada a partir de amostras de solo, água, ar, tecidos vegetais, tecidos animais e outras fontes ${ }^{56}$. Nesse contexto, os recursos oriundos da 


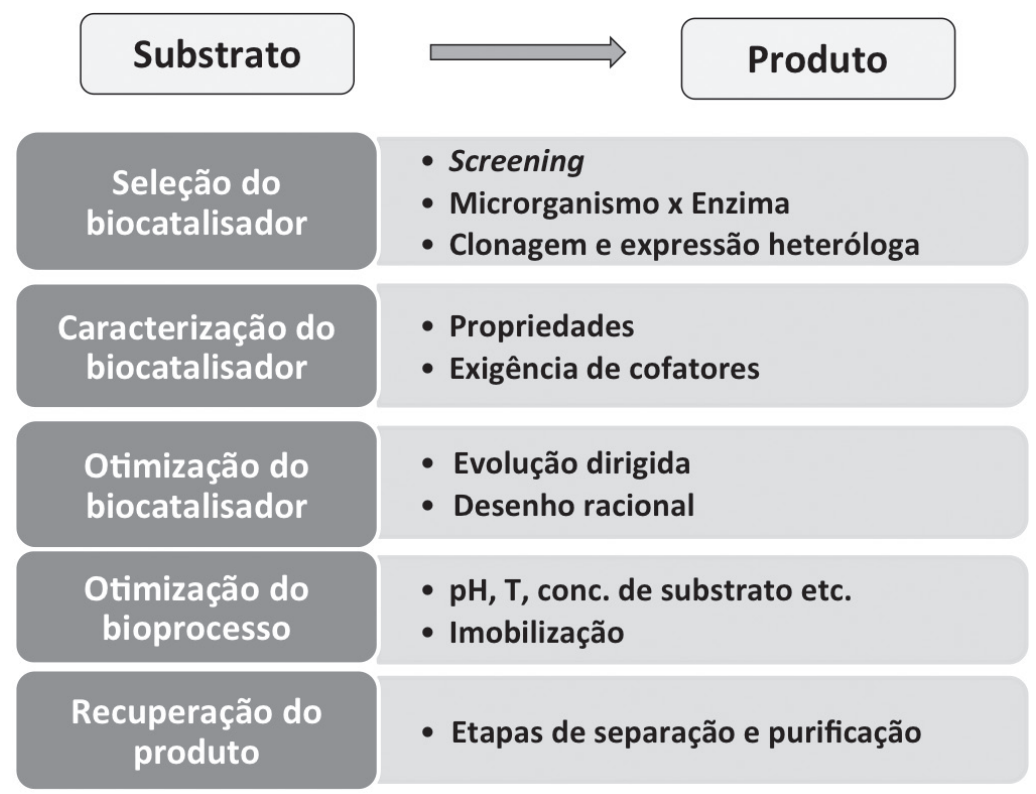

Figura 4.11 Etapas envolvidas no desenvolvimento de um processo biocatalítico.

biodiversidade representam um manancial inesgotável para impulsionar as pesquisas nesta área.

A partir das fontes primárias, ferramentas poderosas como a metagenômica, proteômica e bionformática podem ser utilizadas na construção de bancos de genes que codificam diferentes enzimas, visando a sua produção em grandes quantidades através de clonagem e expressão ${ }^{58}$. A obtenção de catalisadores de interesse industrial está atualmente muito facilitada pelo uso de técnicas de biologia molecular. Assim, uma vez identificada uma enzima de interesse, seu gene pode ser clonado, preferencialmente em leveduras e bactérias, e a proteína catalítica ser expressa em grandes quantidades ${ }^{57,58}$.

A etapa seguinte é a caracterização da enzima quanto às suas propriedades bioquímicas, condições ambientais de atuação, exigência de cofatores, identificação de possíveis ativadores e inibidores, estabilidade etc.

As propriedades do biocatalisador de interesse podem ser melhoradas, alcançando-se maior estabilidade operacional e habilidades catalíticas específicas, através do emprego de técnicas avançadas de evolução dirigida (mimetização do darwinismo in vitro, combinando mutação com seleção de variantes com as propriedades desejadas) e de desenho racional (mutações 
sítio-dirigidas com o intuito de trocar com precisão certos aminoácidos da enzima), aproximando ainda mais a biocatálise do setor industrial $1^{1,36,38,58}$.

A otimização de um processo bioquímico, microbiano ou enzimático, para obtenção do máximo rendimento em produto e produtividade, é uma tarefa complexa. Tradicionalmente, são empregadas abordagens empíricas, nas quais são investigados efeitos da formulação do meio reacional (concentração de substrato, concentração do biocatalisador, presença/concentração de aditivos, força iônica, eventual presença de solventes orgânicos) e dos parâmetros operacionais ( $\mathrm{pH}$, temperatura, tempo, aeração e outros). Os principais inconvenientes desse tipo de abordagem são o grande número de experimentos necessários, a grande demanda de tempo e, principalmente, o fato de os fatores serem investigados individualmente, ignorando-se os efeitos interativos entre eles. Porquanto, é crescente a aplicação, com sucesso, de métodos estatísticos na otimização de bioprocessos. Usualmente, numa primeira etapa os principais parâmetros são selecionados e, a seguir, combinados em faixas mínimas e máximas, de acordo ferramentas estatísticas (planejamento fatorial), que permitem considerar muitas variáveis envolvidas de maneira simultânea. Avaliando-se estatisticamente as respostas pré-selecionadas para traduzir a eficiência do processo, é possível aplicarem-se várias etapas sequenciais de planejamento experimental. Observando-se as tendências assumidas pelo processo a partir da influência de cada variável e das possíveis combinações entre elas, pode-se refinar paulatinamente os resultados em direção à otimização do processo ${ }^{59-62}$.

A recuperação e purificação do produto, especialmente os de uso farmacêutico, representa uma das etapas de maior custo, podendo chegar a $75 \%$ do valor tota ${ }^{10}$. A definição das operações dessa etapa depende de muitos fatores, como: tipo de bioconversão (microbiana, enzimática, biocatalisador livre ou imobilizado); características do produto (tamanho da molécula, concentração, solubilidade, polaridade, volatilidade, entre outras); propriedades físico-químicas do meio reacional (viscosidade, densidade, presença de impurezas e partículas indesejáveis); grau de pureza requerida; e forma final do produto (liofilizado, cristalizado, sólido, líquido concentrado etc.) ${ }^{51,63,64}$.

O cumprimento das etapas da Figura 4.11 revela a relativa complexidade técnica envolvida no uso da tecnologia enzimática ou microbiana em processos de bioconversão. No entanto, dada a constante pressão pela inovação e a busca de alternativas para os poluentes e encarecidos derivados do petróleo, cada vez mais as grandes companhias químicas têm envidado esforços para estabelecer competitividade nesse setor. 


\subsection{CENÁRIO INDUSTRIAL}

\subsubsection{Aplicações industriais precedentes}

$\mathrm{O}$ alicerce científico que permitiu estabelecer bases para os maiores avanços industriais na bioconversão do século XX foram duas descobertas simultâneas realizadas no final dos anos 1950: aquela feita por G. Beadle e E. L. Tatum, que demonstrou que cada enzima produzida por um organismo estava condicionada a um gene específico (hipótese "um gene $\times$ uma enzima"); e a de J. Lederberg, sobre as possibilidades de recombinação genética e a organização genética das bactérias ${ }^{13,65}$. Ambas deram suporte para a descoberta do DNA recombinante por S. N. Cohen e H. Boyer em $1973^{66}$, que gerou a engenharia genética e as possibilidades de clonagem. Essa tecnologia foi rapidamente absorvida nos processos de transformações microbianos, inicialmente para a produção de pequenas moléculas.

Em 1984, a Novozymes desenvolveu uma amilase maltogênica (Maltogenase $\left.{ }^{\circledR}\right)$ como a primeira enzima para uso na indústria de amido obtida de um organismo geneticamente modificado ${ }^{13}$. Em seguida, uma cepa de bactéria foi modificada geneticamente para produzir o ácido 2-ceto-L-gulônico, projetando uma rota bem mais curta para a vitamina $\mathrm{C}$ do que aquela estabelecida cinquenta anos antes a partir do D-sorbitol ${ }^{67}$. Essa se tornou a base para o desenvolvimento da planta de produção estabelecida em 1999 na Alemanha pela BASF, Merck e Cerestar, que fermentava o sorbitol diretamente para 2-ceto-L-gulônico ${ }^{68}$. A tecnologia enzimática ainda foi aplicada na produção da acrilamida e da L-carnitina ${ }^{1}$, estabelecidas pela Nitto Chemical Ltd (Japão) e pela Lonza (República Tcheca), respectivamente. A primeira dessas moléculas é comercializada como commodity, atingindo o amplo mercado de produtos de aditivos e agentes floculantes em geral. O processo desenvolvido em sua obtenção envolve a conversão por Rodococcus sp., numa reação suave, com $100 \%$ de rendimento, além de outras vantagens inerentes a um processo limpo e sustentável. Em resumo, na segunda metade do século XX, um painel com uma dezena de pequenas moléculas obtidas por biotransformação realizada por células íntegras estava disponibilizado por sete grandes empresas (Figura 4.12) ) $^{13}$.

Um setor que rapidamente ganhou importância dentro dos bioprocessos foi a produção de polímeros, com a emblemática obtenção do poli-hidroxibutirato, um polímero de alto valor agregado devido à sua aplicação médica. É obtido pela fermentação de Escherichia coli modificada geneticamente 
para expressar a biossíntese desse composto ${ }^{69}$. O polímero, denominado "Biopol", possui uma tecnologia de produção altamente econômica, detida pela Zeneca Bio Products.<smiles>O=C(CO)[C@H](O)[C@H](O)[C@H](O)CO</smiles>

L-Sorbose

Acetobacter suboxydans (várias empresas)

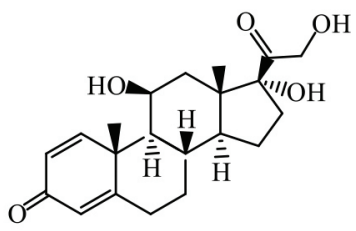

Prednisolona Arthrobacter simplex

(Shering AG)<smiles>N[C@@H](CC(=O)O)C(=O)O</smiles>

Ácido L-aspártico Escherichia coli (Tanabe Seiyaku Co.)<smiles>C[C@@H](N)C(=O)O</smiles>

Alanina Psudomonas dacunhae (Tanabe Seiyaku Co.)<smiles>N[C@@H](CC(=O)O)C(=O)O</smiles>

Ácido D-aspártico Psudomonas dacunhae (Tanabe Seiyaku Co.)<smiles>O=C(O)C[C@H](O)C(=O)O</smiles>

Ácido L-málico Brevibacterium ammoniagenes (Tanabe Seiyaku Co.)<smiles></smiles>

L-Carnitina Agrobacterium sp. (Lonza)<smiles>O=C(CO)C(=O)[C@@H](O)[C@H](O)[C@H](O)CO</smiles>

Ácido 2-ceto-L-gulônico Acetobacter sp. (BASF, Merck, Cerester)<smiles>N[C@@H](C(=O)O)c1ccc(O)cc1</smiles>

D-p-Hidroxif enilglicina Psudomonas striata (Tanabe Seiyaku Co.)<smiles>CC1=C(C(=O)O)N2C(=O)[C@@H](N)[C@H]2SC1</smiles>

Ácido 7-amino-desacetoxy-cefalosporânico

(7-ADCA) - Bacillus megaterium (Asahi Chemical Industry)

Figura 4.12 Moléculas com produção industrial por bioconversões catalisadas por células íntegras, na segunda metade do século XX. Figura elaborada com base em Vasic-Racki, $2006^{13}$. 
Por seu lado, a aplicação de enzimas em processos industriais mais recentes tem seu marco inicial na produção do golden syrup ("xarope dourado") pela companhia inglesa Tate \& Lyle, durante a Segunda Grande Guerra, utilizando uma invertase adsorvida em carvão animal ${ }^{70}$. O produto é uma mistura de glicose e frutose (1,5 vezes mais doce que a sacarose) originada pela inversão da sacarose induzida por uma enzima, que então substituía o papel hidrolítico do ácido sulfúrico sobre o dissacarídeo. Esse pode ter sido também o primeiro uso industrial de uma enzima imobilizada. Poucos anos depois, ocorreu a produção de aminoácidos a partir da ação hidrolítica da aminoacilase sobre aminoácidos acilados. Essa enzima também era imobilizada em uma fase contendo Sephadex e empacotada no biorreator ${ }^{71}$. Em<smiles>CC(C)CCCCCCCCCCCCCCC(=O)N[C@H]1C(=O)N2C1SC(C)(C)C2C(=O)O</smiles>
penicilina
acilase<smiles>O=C(O)Cc1ccccc1</smiles>

$+$<smiles>CC1(C)SC2[C@H](N)C(=O)N2C1C(=O)O</smiles>
6-APA<smiles>CC(=O)OC1=C(C(=O)O)N2C(=O)[C@@H](NC(=O)CCCC(N)C(=O)O)[C@H]2SC1</smiles>

D-aminoácido oxidase

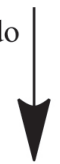<smiles>CC(=O)OC1=C(C(=O)O)N2C(=O)[C@@H](NC(=O)CCCC(N)O)C2SC1</smiles>

\footnotetext{
.
}

Figura 4.13 Obtenção dos precursores $\beta$-lactâmicos 6-APA e 7-APA por via enzimática. 
1966, a mesma empresa japonesa que desenvolveu o uso da aminoacilase, a Tanabe Seiyaku, refinou o processo e aumentou a proporção de frutoses nos xaropes, por intermédio da ação da glicose isomerase sobre $\alpha$-D-glicose. Um ano depois, a Clinton Corn Processing Company introduziu no mercado um "xarope dourado" inteiramente obtido por ação enzimática sobre o xarope bruto de milho ${ }^{71}$.

As crescentes tentativas de imobilizar enzimas, inicialmente para a produção de aminoácidos, viriam a contribuir também para os avanços da engenharia dos bioprocessos, levando, por exemplo, à projeção de sistemas de reator com membrana, na Alemanha, na década de $1980^{72}$. As possibilidades de filtrações seletivas em pontos estratégicos do fluxo operacional da bioconversão traz uma série de vantagens aos processos e produtos finais.

Paralelamente, outros avanços na engenharia deveram-se à necessidade de acoplar aos bioprocessos as operações de separação e purificação de produtos. Por exemplo, os sucessivos enriquecimentos do "xarope dourado" em frutose levaram à purificação dessa substância por cristalização e, posteriormente, ao surgimento de uma enzima comercial, imobilizada e altamente estável, a "Sweetzyme T". Esta é produzida pela empresa dinamarquesa Novo para aplicação na indústria de amidos, visando produzir xaropes com altos teores de frutose ${ }^{13}$. Outro exemplo de sucesso de enzima imobilizada é a lactase, obtida de levedura, que hidrolisa a lactose (de baixa solubilidade e pouco doce) para uma mistura de glicose e galactose. Esse processo permitiu que uma companhia italiana situada em Milão fosse a primeira a comercializar leite livre de lactose $^{73}$.

$\mathrm{Na}$ área farmacêutica, o exemplo mais proeminente é sem dúvida a produção dos intermediários ácido 6-aminopenicilânico (6-APA), ácido 7-aminocefalosporânico (7-ACA) e ácido 7-amino-desacetoxicefalosporânico (7-ADCA). Trata-se de três moléculas-chaves para a semissíntese de inúmeros derivados de antibióticos $\beta$-lactâmicos, nos processos de busca por moléculas mais efetivas ou de mais amplo espectro contra patógenos cada vez mais resistentes. O processo hoje em voga para produzir 6-APA é o mesmo de cinquenta anos atrás e envolve a ação da penicilina acilase sobre a penicilina G ou V. O 7-ACA é obtido usando-se como material de partida a cefalosporina $\mathrm{C}$ e seu tratamento sequencial é operacionalmente controlado com duas enzimas distintas, conforme foi desenvolvido pela parceria entre as empresas japonesas Toyo Jozo e a Asahi Chemical Industry (Figura 4.13) ${ }^{70}$. Em ambas as etapas, as vantagens econômicas e ambientais são enormes. 


\subsubsection{Possibilidades industriais}

Ainda nos dias de hoje, considera-se que o trabalho de desenvolver um bioprocesso e conduzi-lo apropriadamente à produção e comercialização de algum insumo pode demorar até vinte anos ${ }^{1,13,74}$. Mesmo com esse panorama, os exemplos de processos desenvolvidos na metade final do século XX multiplicaram-se para alcançar, até 2006, mais de 150 processos estabelecidos em escala industrial ${ }^{13}$. Parte das razões desse crescimento, em menor período de tempo, é o próprio acúmulo de know-how naturalmente decorrente dos esforços precedentes em transformar resultados de pesquisas em tecnologias viáveis. Há que considerar também as frequentes inovações incrementais, relacionadas a reações específicas e materiais diversos envolvidos nas várias etapas que compõem os processos catalíticos (Figura 4.11). Complementarmente, a engenharia dos bioprocessos deve considerar os fundamentos científicos da engenharia voltados para desenvolver processos, produtos e serviços relacionados à indústria química e farmacêutica, de maneira racional, sustentável e segura. Além disso, sempre é fundamental, para uma indústria, a redução de custos de seus processos, de maneira geral.

Em termos de volume de produção, o mercado atual é representado por produtos resultantes de bioconversões voltadas para a área de alimentos, principalmente a produção de carboidratos, que ultrapassa 10.000 ton/ ano. Logo em seguida aparecem a acrilamida (monômero) e o intermediário 6-APA, com produções que modulam entre 100 ton/ano e 10.000 ton/ ano, considerando-se as dezenas de processos de bioconversões existentes. Já em termos de diversidade molecular, a maioria das bioconversões industriais gera produtos para a química fina, apontando para o setor farmacêutico (com alguma inserção de cosméticos) como o principal responsável por essa demanda ${ }^{11}$. Em termos de valor agregado, as moléculas de apelo farmacêutico - que atuarão como princípios ativos em medicamentos ou em intermediários para obtê-los -, ainda que produzidas em menor volume, contrabalançam os valores gerados pelos produtos destinados ao mercado de alimentos.

Existe também o mercado específico das enzimas. Por exemplo, as hidrolases são as enzimas mais utilizadas na biotransformação industrial, considerando-se suas subclasses de lipases, proteases, amidases e glicosidases, destinadas a produtos específicos para o mercado. Aqui, são relevantes a hidrólise dos polissacarídeos em açúcares monoméricos e a fabricação de acrilamida (hidrólise do grupo nitrila), que respondem por um mercado amplo. As liases e transferases também estão entre as mais utilizadas. Podem ser exploradas para construir 
moléculas e criar centros quirais, e por isso são importantes nas sínteses assimétricas e de fármacos. Contudo, são usadas preferencialmente quando inseridas em células, já que assim os requisitos por ATP ou outros cofatores estarão preenchidos. Essa preferência por sistemas envolvendo células também se dá para as oxidorredutases, já que as células podem usar o metabolismo primário para regenerar os cofatores redox ${ }^{11}$. Uma subclasse bastante importante de enzima são as monoxigenases, capazes de catalisar, de forma eficiente e específica, a inserção de um átomo de oxigênio em cadeias alifáticas de compostos orgânicos, reação de difícil obtenção em síntese orgânica ${ }^{75-78}$.

Sem dúvida, o principal aspecto da aplicação de sistemas de bioconversão na área farmacêutica é a obtenção de compostos quirais de interesse. Assim, desidrogenases, dehalogenases, monoxigenases, dioxigenases, acilases, amidases, lipases, nitrilases, liases, epóxido-hidrolases, descarboxilases, hidantoinases, oxidorredutases, transaminases aldolases e catalase, entre outras, têm sido estudadas para: resolução de compostos racêmicos; síntese assimétrica de compostos quirais enriquecidos enantiomericamente; síntese de alcoóis, amino alcoóis, aminoácidos e aminas quirais; síntese assimétrica por condensação aldólica e condensação aciloínica; hidroxilação e epoxidação enantio e régio seletivas; síntese quimioenzimática de dióis quirais $3,4,6,7,79,80$.

Um denominador comum à totalidade dos processos industriais com base em catálise enzimática é a busca da seletividade na bioconversão, que pode envolver aspectos de regiosseletividade e quiralidade. As possibilidades de aplicação dessa tecnologia são tão amplas quanto a gama de enzimas existentes, sejam elas já isoladas e disponíveis, incorporadas em micro-organismos ou expressadas por estes. O planejamento de uma bioconversão pode ser inferido a partir das etapas da Figura 4.11, avaliando-se a natureza do produto que se objetiva obter, na perspectiva das características gerais dos bioprocessos e suas modalidades. Assim, devem-se considerar, entre outros desdobramentos, as seguintes questões:

- seleção do sistema da bioconversão, com emprego de enzimas ou de células íntegras;

- planejamento para se atingir a eficiência ótima do processo selecionado (que pode ser ensaiado, numa etapa de prospecção);

- questões técnicas imediatas como condições reacionais, imobilização do agente bioconversor, custo e disponibilidade do catalisador, esforços necessários para separação e purificação do produto etc;

- requisitos de engenharia necessários para executar o projeto; e

- valor agregado do produto. 


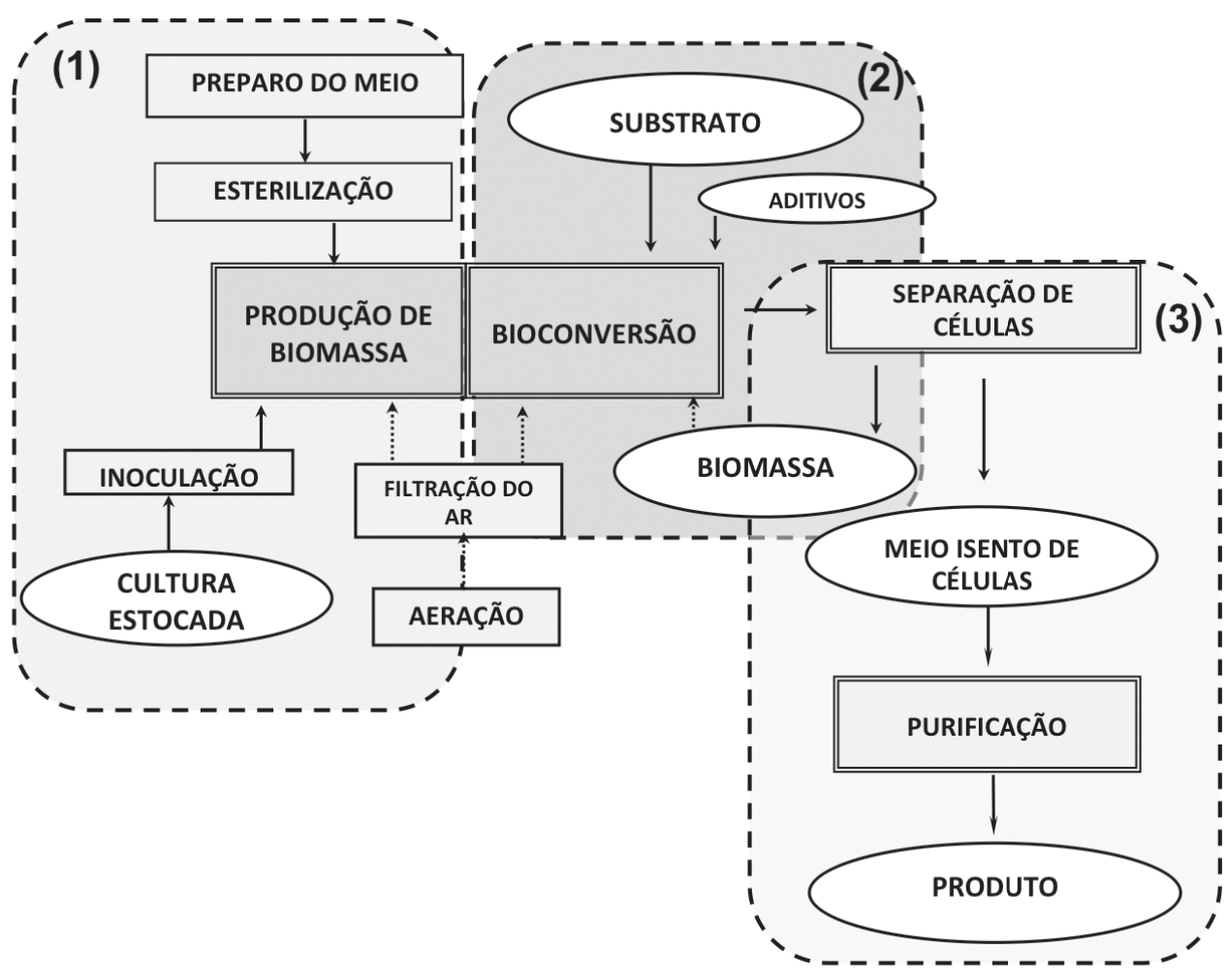

Figura 4.14 Representação esquemática de um processo de bioconversão microbiana: (1) produção de massa celular; (2) bioconversão; e (3) separação e purificação do produto.

Por fim, o custo-benefício do processo deve justificar os investimentos, o que implica em estratégias de inovação que extrapolam as questões técnicas, como conhecer processos competitivos, concorrentes, nichos de mercado etc.

\subsection{PROTOCOLO GERAL PARA A TÉCNICA}

Esta seção apresenta, de maneira resumida e esquemática, uma orientação geral para executar os processos de bioconversão, descrevendo de maneira genérica as etapas necessárias. Também são abordados apenas os casos com biocatalisador livre em sistemas aquosos. Obviamente, há cuidados que concernem às especificidades de cada processo reacional em particular. 
Detalhamentos dos sistemas, como o emprego de diferentes enzimas etc., são cobertos pelas referências citadas ao longo do texto.

\subsubsection{Bioconversão microbiana}

O processo de bioconversão microbiana compreende diversas operações, as quais podem ser divididas em três conjuntos principais, representados pelos blocos na Figura 4.14: (1) a produção de massa celular; (2) o processo em si de bioconversão; e (3) as etapas de separação e purificação do produto.

O primeiro conjunto de operações consiste na produção de massa celular e compreende o preparo e a esterilização do meio de propagação, o preparo do inóculo e a produção celular propriamente dita.

É importante notar que a manutenção e a preservação dos micro-organismos são etapas de extrema importância para assegurar a sua viabilidade e prevenir mudanças genéticas que levem à redução ou perda de propriedades fenotípicas. Técnicas de manutenção e conservação de micro-organismos são descritas na literatura e incluem repicagens periódicas, conservação em parafina ou em glicerol, liofilização e crioconservação ${ }^{59}$.

As características e necessidades nutricionais variam entre os micro-organismos, e aquelas do micro-organismo de interesse devem ser muito bem conhecidas para que a etapa de produção de biomassa seja cumprida com sucesso. De maneira geral, para o crescimento de um micro-organismo é necessário o suprimento de água, fontes de carbono e energia, nitrogênio, oxigênio, elementos minerais (fósforo, enxofre, potássio, cálcio, magnésio, sódio, ferro, entre outros), elementos traços (manganês, cobre, zinco, molibdênio, cromo, níquel, cobalto, boro, entre outros); além de fatores de crescimento, quando necessários (certos aminoácidos, purinas, pirimidinas ou vitaminas que o micro-organismo em questão não seja capaz de sintetizar ${ }^{81,82}$. Para prevenir contaminações, o bioprocesso é conduzido em condições assépticas. Dessa forma, o meio de cultura, assim como o ar (em processos aeróbicos), deve ser esterilizado antes de fornecido à cultura ${ }^{51,56,64,83}$.

$\mathrm{O}$ crescimento microbiano pode ser realizado em cultivos submersos ou cultivos no estado sólido, sendo os primeiros os mais utilizados. Nesse caso, as fermentações são conduzidas em frascos agitados (em escala de laboratório) ou em biorreatores aerados e agitados mecanicamente, seja em escala de laboratório, piloto ou industrial. Os parâmetros operacionais, tais como $\mathrm{pH}$, temperatura, consumo de oxigênio e formação de dióxido de carbono, devem ser medidos e controlados de maneira a garantir a manutenção das condições 
ótimas de cultivo dos micro-organismos. Os bioprocessos submersos podem ser operados em modos de batelada simples, batelada alimentada ou condução contínua, visando atingir altos rendimentos e produtividade adequada em células. Fundamentos teóricos e aspectos práticos sobre cultivos de micro-organismos em escala de laboratório e industrial, incluindo todas as etapas envolvidas, estão amplamente descritos na literatura ${ }^{51,56,64,83}$.

Uma vez obtido o biocatalisador (células íntegras), é então iniciada a etapa de bioconversão propriamente dita (etapa 2 da Figura 4.14). Caso haja necessidade de substituir o meio reacional utilizado no crescimento celular, a separação das células pode ser efetuada por centrifugação, filtração, sedimentação ${ }^{51,63,64}$. Nesta etapa são adicionados o substrato a ser transformado, os aditivos específicos para a reação de interesse e, caso se trate de uma reação de oxidação, o suprimento de ar no reator. $\mathrm{O}$ pH, a temperatura e, eventualmente, a concentração de oxigênio dissolvido devem ser monitorados e corrigidos, de forma a garantir a manutenção das condições ótimas determinadas para o processo. Da mesma forma que o cultivo celular, a bioconversão pode ser operada nos modos de batelada simples,

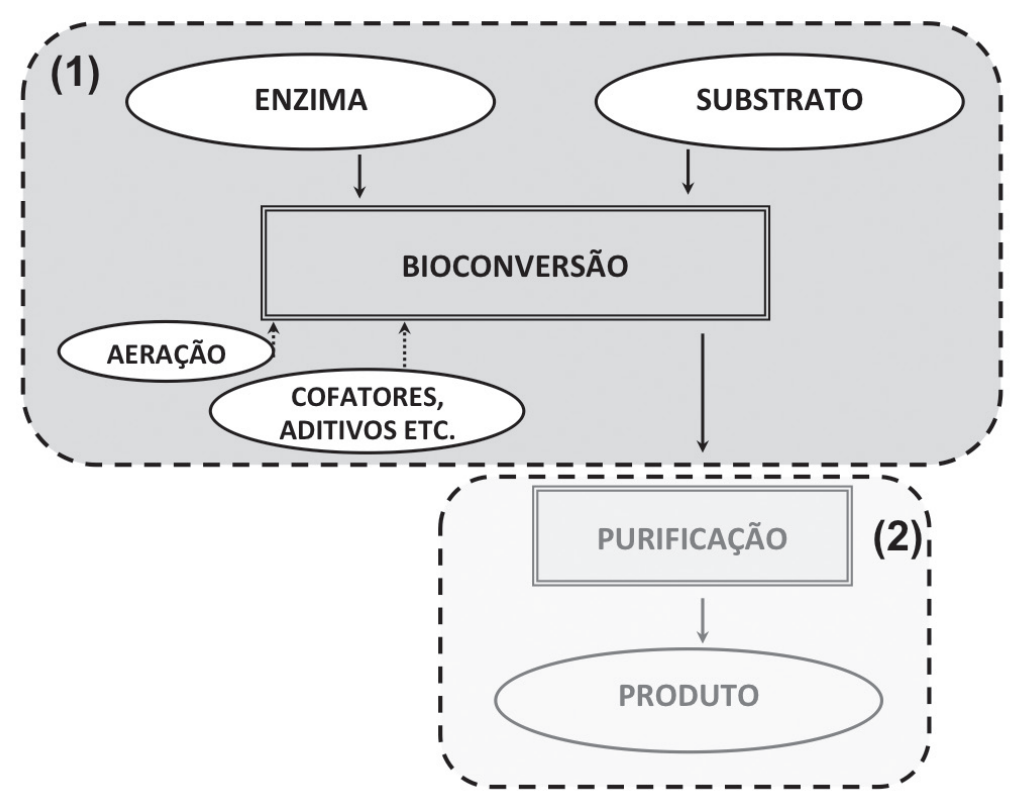

Figura 4.15 Representação esquemática de um processo de bioconversão enzimática. (1) Bioconversão; e (2) separação e purificação do produto. 
batelada alimentada ou condução contínua, visando atingir altos rendimentos e produtividade.

Segue-se então o conjunto de etapas de isolamento e purificação do produto (etapa 3 da Figura 4.14), cujo primeiro passo é uma separação sólido líquido para retirar as células, que podem ser recicladas para uma nova bioconversão. A etapa seguinte é a concentração do produto, realizada por precipitação, filtração em membranas ou extração líquido-líquido. Segue-se a etapa de purificação final, efetuada por cromatografia ou cristalização. Conforme já mencionado, as características físico-químicas do produto e do meio reacional, assim como o grau de pureza pretendido, irão determinar os procedimentos que serão adotados. A literatura especializada em bioprocessos descreve detalhadamente essas operações ${ }^{51,64,83}$.

\subsubsection{Bioconversão enzimática}

O processo de bioconversão enzimática é bem mais simplificado quando comparado à bioconversão microbiana. A primeira compreende apenas as etapas de bioconversão propriamente dita, sendo complementada com o isolamento e purificação do produto final, subentendendo-se que o biocatalisador, constituído de enzima(s) isolada(s), foi adquirido no mercado ou produzido in loco em uma etapa separada (Figura 4.15). Detalhes sobre os múltiplos aspectos relacionados à produção de enzimas podem ser encontrados na literatura ${ }^{1,56}$.

A diferença fundamental entre a bioconversão enzimática e a microbiana é que esta última contém partículas em suspensão (células microbianas), enquanto na primeira o catalisador está dissolvido no meio reacional. Todos os outros aspectos já abordados para a bioconversão microbiana se aplicam à enzimática.

\subsection{PERSPECTIVAS}

Apesar da importância fundamental que vem assumindo, a aplicação de processos de bioconversão em escala industrial está, contudo, em sua infância. O número de micro-organismos e sistemas enzimáticos avaliados até o momento ainda é ínfimo considerando-se o potencial existente. Ressalte-se também o custo ainda bastante elevado das enzimas disponíveis no mercado. 
Assim, entre as ações que podem impulsionar a introdução de novas enzimas e organismos voltados para a finalidade da bioconversão, estão:

- Intensificar a triagem tradicional para identificar novos biocatalisadores promissores, a partir de buscas em nichos inexplorados da biodiversidade; o que inclui a prospecção de organismos extremófilos, que crescem em ambientes inóspitos.

- Combinar técnicas modernas de prospecção (bigh throughput screening) com ferramentas de bioinformática e metagenômica para acessar novas espécies microbianas e identificar novas enzimas.

- Utilizar ferramentas da biologia molecular (clonagem molecular, mutagênese dirigida ou randômica, evolução dirigida de biocatalisadores) para ampliar as possibilidades de recombinação genética e gerar, de maneira eficiente e com apelo industrial, micro-organismos e enzimas feitos "sob medida" (tailor-made) para aplicações específicas.

- Acumular informações sobre organismos-enzimas, agregando dados obtidos através de estudos sobre genomas, transcriptomas, proteomas e metabolomas.

- Estimular os estudos de predição estrutura-função, visando ampliar o acesso à variedade de enzimas para uso como ferramentas de síntese orgânica.

- Desenvolver novas e eficientes técnicas para reciclagem de cofatores.

- Incentivar estudos aplicados nas áreas de química e bioquímica de proteínas, assim como de engenharia bioquímica.

A necessidade do desenvolvimento autossustentável, que pressupõe o uso de matérias-primas renováveis por processos que gerem produtos de qualidade com tecnologias limpas, às crescentes regulamentações governamentais e o estímulo oferecido pelo preço crescente da energia e progresso científico nesta área deverão certamente impulsionar o desenvolvimento dessas novas tecnologias. 


\section{REFERÊNCIAS}

1. Bommarius AS, Riebel-Bommarius BR. Biocatalysis: Fundamentals and Applications. Weinheim: Wiley-VCH Verlag GmbH \& Co. KGaA; 2007.

2. Ishige T, Honda K, Shimizu S. Whole organism biocatalysis. Current Opinion in Chemical Biology. 2005;9(2):174-80.

3. Loughlin WA. Biotransformations in organic synthesis. Bioresource Technology. 2000;74(1):49-62.

4. Patel RN. Microbial/enzymatic synthesis of chiral intermediates for pharmaceuticals. Enzyme and Microbial Technology. 2002;31(6):804-26.

5. Schmid A, Dordick JS, Hauer B, Kiener A, Wubbolts M, Witholt B. Industrial biocatalysis today and tomorrow. Nature. 2001;409(6817):258-68.

6. Fessner WD, Anthonsen T. Modern Biocatalysis: Stereoselective and Environmentally Friendly Reactions. Weinheim: Wiley-VCH Verlag GmbH \& Co. KGaA; 2008.

7. Faber K. Biotransformations. U.S. Government Printing Office; 2000.

8. Meyer H-P, Ghisalba O, Leresche JE. Biotransformations and the Pharma Industry. Handbook of Green Chemistry. Weinheim: Wiley-VCH Verlag GmbH \& Co. KGaA; 2010.

9. Sanchez S, Demain AL. Enzymes and bioconversions of industrial, pharmaceutical, and biotechnological significance. Organic Process Research and Development. 2011;15(1):224-30.

10. Kircher M. The pharmaceutical industry needs more innovation in bioprocesses. Future Medicinal Chemistry. 2011;3(14):1737-40.

11. Straathof AJJ. Quantitative Analysis of Industrial Biotransformation. In: Liese A, Seelbach K, Wandrey C, editors. Industrial Biotransformations. Weinheim, FRG: WileyVCH Verlag GmbH \& Co. KGaA; 2006.

12. Straathof AJ, Panke S, Schmid A. The production of fine chemicals by biotransformations. Curr Opin Biotechnol. 2002;13(6):548-56.

13. Vasic-Racki D. History of Industrial Biotransformations-Dreams and Reality. In: Liese A, Seelbach K, Wandrey C, editors. Industrial biotransformatios. Weinheim: WileyVCH Verlag GmbH \& Co. KGaA; 2006. p. 1-36.

14. Pasteur L. Mémoire sur la fermentation de l'acide tartrique. C. R. Académie des Sciences. 1858;46:615-8.

15. Pasteur L. Suite a une precedente communication sur les mycodermes; nouveau procédé industriel de fabrication du vinaigre. Comptes Rendus des Séances de l'Académie des Sciences. 1862;55:28-32.

16. Sebek OK. Notes on historical development of microbial transformation. In: Rosazza JP, editor. Microbial transformations of bioreactive compounds. Boca Raton: CRC-Press; 1982. p. 2-6. 
17. Perham RN. The protein chemistry of enzymes. FEBS letters. 1976;62(Suppl):E20-9. 18. Buchner E. Alkoholische garung ohne hefezellen. Ber Che Ges. 1897;30 (117):1110. 19. Fischer E. Einfluss der Configuration auf die Wirkung der Enzyme. Berichte der deutschen chemischen Gesellschaft. 1894;27(3):2985-93.

20. Fischer E. Synthesen in der Zuckergruppe II. Berichte der deutschen chemischen Gesellschaft. 1894;27(3):3189-232.

21. Michaelis L, Menten ML, Johnson KA, Goody RS. The original Michaelis constant: translation of the 1913 Michaelis-Menten paper. Biochemistry. 2011 Oct 4;50(39):8264-9.

22. Briggs GE, Haldane JB. A Note on the Kinetics of Enzyme Action. The Biochemical Journal. 1925;19(2):338-9.

23. Laidler KJ. A Brief History of Enzyme Kinetics. In: Cornish-Bowden A, editor. New Beer in an Old Bottle: Eduard Buchner and the Growth of Biochemical Knowledge. Valencia: Universitat de València; 1997. p. 127-33.

24. Sumner JB. The Isolation and Crystallization of the Enzyme Urease: Preliminary Paper. Journal of Biological Chemistry. 1926;69(2):435-41.

25. Gutte B, Merrifield RB. Total synthesis of an enzyme with ribonuclease A activity. Journal of the American Chemical Society. 1969;91(2):501-2.

26. Mitchell CA. Vinegar: Its Manufacture and Examination. London: C. Griffin, Limited; 1926.

27. Mori A. Vinegar production in a fluidized bed reactor with imobilized bacteria.

In: Tanaka A, Tosa T, Kobayashi T, editors. Industrial Application of Immobilized Biocatalysts. New York: Taylor \& Francis; 1992. p. 291-313.

28. Ebner H, Sellmer S, Follmann H. Acetic acid. In: Rehm HJ, Reed G, Roehr M, editors. Biotechnology: Products of primary metabolism. Weinheim: VCH; 1996. p. 383. 29. Sheldon RA. Chirotechnology: Industrial Synthesis of Optically Active Compounds. New York: Taylor \& Francis; 1993.

30. Neuberg C, Hirsch J. Über ein Kohlenstoffketen knüpfendes ferment (carboligase). Biochem Z. 1921;115:282-310.

31. Kluyver AJ, de Leeuw FJG. Acetobacter suboxydans, een merkwaardige azijnbacterie. S.n.; 1923.

32. Peterson DH, Murray HC, Eppstein SH, Reineke LM, Weintraub A, Meister PD, et al. Microbiological Transformations of Steroids.1 I. Introduction of Oxygen at Carbon-11 of Progesterone. Journal of the American Chemical Society. 1952;74(23):5933-6.

33. Sebek OK, Perlman D. Microbial Transformation of Steroids and Sterols. In: Peppler HJ, Perlman D, editors. Microbial Technology: Microbial processes. New York: Academic Press; 1979. p. 484-8.

34. de Carvalho CCCR, da Fonseca MMR. Biotransformation of terpenes. Biotechnology Advances. 2006;24(2):134-42. 
35. Wang Y-J, Zheng Y-G, Xue J-P, Shen Y-C. Microbial transformation of indole3-acetonitrile to indole-3-acetamide by Nocardia sp. 108. Process Biochemistry. 2006;41(8):1746-50.

36. Carballeira JD, Quezada MA, Hoyos P, Simeo Y, Hernaiz MJ, Alcantara AR, et al. Microbial cells as catalysts for stereoselective red-ox reactions. Biotechnology Advances. 2009;27(6):686-714.

37. Ferrara MA, Lacerda PSB, Freitas A, Bon EPS. Microbial bioconversion for pharmaceuticals and chiral intermediates. Current Topics in Biotechnology. 2007;3:57-65.

38. Fernandes P, Aires-Barros MR, Cabral JMS. Biocatálise Aplicada. In: Lima N, Mota M, editors. Biotecnologia: Fundamentos e Aplicações. Lisboa: Lidel; 2003.

39. Olivier-Bourbigou H, Magna L, Morvan D. Ionic liquids and catalysis: Recent progress from knowledge to applications. Applied Catalysis A: General. 2010;373(1-2):1-56.

40. Cull SG, Holbrey JD, Vargas-Mora V, Seddon KR, Lye GJ. Room-temperature ionic liquids as replacements for organic solvents in multiphase bioprocess operations. Biotechnology and Bioengineering. 2000;69(2):227-33.

41. Sureshkumar M, Lee C-K. Biocatalytic reactions in hydrophobic ionic liquids. Journal of Molecular Catalysis B: Enzymatic. 2009;60(1-2):1-12.

42. van Rantwijk F, Madeira Lau R, Sheldon RA. Biocatalytic transformations in ionic liquids. Trends in Biotechnology. 2003;21(3):131-8.

43. Lou WY, Chen L, Zhang BB, Smith TJ, Zong MH. Using a water-immiscible ionic liquid to improve asymmetric reduction of 4-(trimethylsilyl)-3-butyn-2-one catalyzed by immobilized Candida parapsilosis CCTCC M203011 cells. BMC Biotechnology. 2009;9:90.

44. Lue B-M, Guo Z, Xu X. Effect of room temperature ionic liquid structure on the enzymatic acylation of flavonoids. Process Biochemistry. 2010;45(8):1375-82.

45. Paula BRSd, Zampieri DS, Zukerman-Schpector J, Tiekink ERT, Rodrigues JAR, Moran PJS. Knoevenagel condensation of aromatic aldehydes with ethyl 4-chloro-3oxobutanoate in ionic liquids. Journal of the Brazilian Chemical Society. 2012;23:825-30. 46. Zampieri DS, de Paula BRS, Zampieri LA, Vale JA, Rodrigues JAR, Moran PJS. Enhancements of enantio and diastereoselectivities in reduction of (Z)-3-halo-4-phenyl3-buten-2-one mediated by microorganisms in ionic liquid/water biphasic system. Journal of Molecular Catalysis B: Enzymatic. 2013;85-86(0):61-4.

47. Mirata MA, Heerd D, Schrader J. Integrated bioprocess for the oxidation of limonene to perillic acid with Pseudomonas putida DSM 12264. Process Biochemistry. 2009;44(7):764-71.

48. Castro HF, Zanin GM, Moraes FF, Sá-Pereira P. Imobilização de Enzimas e sua Estabilização. In: Bon EPS, Ferrara MA, Corvo ML, Vermelho AB, Paiva CLA, Alencastro 
RB, et al., editors. Enzimas em Biotecnologia - Produção, Aplicações e Mercado. Rio de Janeiro: Interciência; 2008.

49. Hanefeld U. Immobilization as a Tool for Improving Enzymes. In: Fessner WD, Anthonsen T, editors. Modern Biocatalysis. Weinheim: Wiley-VCH Verlag GmbH \& Co. KGaA; 2009. p. 21-41.

50. Thomsen MS, Nidetzky B. Continuous-Flow Microchannel Reactors with SurfaceImmobilized Biocatalysts. In: Fessner WD, Anthonsen T, editors. Modern Biocatalysis. Weinheim: Wiley-VCH Verlag GmbH \& Co. KGaA; 2009. p. 43-54.

51. Pereira Jr N, Bon EPS, Ferrara MA. Tecnologia de Bioprocessos. Pereira Jr N, editor. Rio de Janeiro: Escola de Química/UFRJ; 2008.

52. Abarzúa EGO, Andrade LH, Villela Filho M. Enzimas em Síntese Orgânica. In: Bon EPS, Ferrara MA, Corvo ML, Vermelho AB, Paiva CLA, Alencastro RB, et al., editors. Enzimas em Biotecnologia - Produção, Aplicações e Mercado. Rio de Janeiro: Interciência; 2008.

53. Truppo MD. Cofactor Recycling for Enzyme Catalyzed Processes. In: Carreira EM, Yamamoto H, editors. Comprehensive Chirality. Amsterdam: Elsevier; 2012. p. 46-70.

54. Roche J, Groenen-Serrano K, Reynes O, Chauvet F, Tzedakis T. NADH regenerated using immobilized FDH in a continuously supplied reactor - Application to 1-lactate synthesis. Chemical Engineering Journal. 2014;239:216-25.

55. Liu W, Wang P. Cofactor regeneration for sustainable enzymatic biosynthesis. Biotechnology advances. 2007;25(4):369-84.

56. Bon EPS, Pereira Jr. N, Gottschalk LMF, Sá-Pereira P, Roseiro JC, Ferrara MA. Bioprocessos para a Produção de Enzimas. In: Bon EPS, Ferrara MA, Corvo ML, Vermelho AB, Paiva CLA, Alencastro RB, et al., editors. Enzimas em Biotecnologia Produção, Aplicações e Mercado. Rio de Janeiro: Interciência; 2008.

57. Torres FAG, Moraes LMP, Marco JL, Poças-Fonseca MJ, Felipe MSS. O Uso de Leveduras e Fungos Filamentosos para Expressão Heteróloga de Enzimas. In: Bon EPS, Ferrara MA, Corvo ML, Vermelho AB, Paiva CLA, Alencastro RB, et al., editors. Enzimas em Biotecnologia - Produção, Aplicações e Mercado. Rio de Janeiro: Interciência; 2008. 58. Paiva CLA, Sá-Pereira P. A Aplicação da Biologia Molecular na Produção de Enzimas. In: Bon EPS, Ferrara MA, Corvo ML, Vermelho AB, Paiva CLA, Alencastro RB, et al., editors. Enzimas em Biotecnologia - Produção, Aplicações e Mercado. Rio de Janeiro: Interciência; 2008.

59. Demain AL, Solomon NA. Manual of Industrial Microbiology and Technology. Washington: American Society for Microbiology; 1986.

60. Bicas J, Barros F, Wagner R, Godoy H, Pastore G. Optimization of R-(+)- $\alpha-$ terpineol production by the biotransformation of R-(+)-limonene. Journal of Industrial Microbiology \& Biotechnology. 2008;35(9):1061-70. 
61. Rodrigues MI, Lemma AF. Planejamento de Experimentos e Otimização de Processos. Uma estratégia sequencial de planejamentos. Campinas: Casa do Pão Editora; 2005. 62. Rottava I, Cortina PF, Martello E, Cansian RL, Toniazzo G, Antunes OA, et al. Optimization of alpha-Terpineol production by the biotransformation of R-(+)-limonene and (-)-beta-pinene. Applied biochemistry and biotechnology. 2011 Jun;164(4):514-23. 63. Aires-Barros MR, Cabral JMS. Biosseparações. In: Lima N, Mota M, editors. Biotecnologia: Fundamentos e Aplicações. Lisboa: Lidel; 2003.

64. Schmidell W, Lima UA, Aquarone E, Borzani W. Biotecnologia Industrial. Vol. 2. Engenharia Bioquímica. São Paulo: Blucher; 2001.

65. Beadle GW, Tatum EL. Genetic Control of Biochemical Reactions in Neurospora. Proceedings of the National Academy of Sciences. 1941;27(11):499-506.

66. Cohen SN, Chang ACY, Boyer HW, Helling RB. Construction of Biologically Functional Bacterial Plasmids In Vitro. Proceedings of the National Academy of Sciences. $1973 ; 70(11): 3240-4$.

67. Anderson S, Marks CB, Lazarus R, Miller J, Stafford K, Seymour J, et al. Production of 2-Keto-L-Gulonate, an Intermediate in L-Ascorbate Synthesis, by a Genetically Modified Erwinia herbicola. Science. 1985;230(4722):144-9.

68. McCoy M. Chemical Makers Try Biotech Paths. Chemical \& Engineering News Archive. 1998;76(25):13-9.

69. Martin DP, Williams SF. Medical applications of poly-4-hydroxybutyrate: a strong flexible absorbable biomaterial. Biochemical Engineering Journal. 2003;16(2):97-105.

70. Cheetham PSJ. The application of enzymes in industry. In: Wiseman A, editor. Handbook of enzyme biotechnology. London: Ellis Horwood; 1995. p. 493-8.

71. Trevan MD. Immobilized enzymes: An introduction and applications in biotechnology. New York: John Wiley \& Sons; 1980.

72. Bommarius AS, Drauz K, Groeger U, Wandrey C. Membrane Bioreactors for the Production of Enantiomerically Pure alpha-Amino Acids. In: Collins AN, Sheldrake GN, Crosby J, editors. Chirality in Industry. New York: John Wiley; 1992. p. 372-97.

73. Marconi W, Morisi F. Industrial Applications of Fiber-Entrapped Enzymes. In: Wingard LB, Katchalski-Katzir E, Goldstein L, editors. Applied Biochemistry and Bioengineering. Oxford: Academic Press; 1979. p. 219-58.

74. Ikemi M. Industrial chemicals: enzymatic transformation by recombinant microbes. Bioprocess technology. 1994;19:797-813.

75. Alphand V, Fraaije MW, Mihovilovic MD, Ottolina G. Second Generation BaeyerVilliger Biocatalysts. Modern Biocatalysis: Wiley-VCH Verlag GmbH \& Co. KGaA; 2009. p. 339-68.

76. Sakaki T. Practical application of cytochrome P450. Biological \& pharmaceutical bulletin. 2012;35(6):844-9. 
77. Torres Pazmiño DE, Winkler M, Glieder A, Fraaije MW. Monooxygenases as biocatalysts: Classification, mechanistic aspects and biotechnological applications. Journal of biotechnology. 2010;146(1-2):9-24.

78. Schewe H, Mirata MA, Holtmann D, Schrader J. Biooxidation of monoterpenes with bacterial monooxygenases. Process Biochemistry. 2011;46(10):1885-99.

79. Lacerda PSB, Ribeiro JB, Leite SGF, Ferrara MA, Coelho RB, Bon EPS, et al. Microbial reduction of ethyl 2-oxo-4-phenylbutyrate. Searching for R-enantioselectivity. New access to the enalapril like ACE inhibitors. Tetrahedron: Asymmetry. 2006;17(8):1186-8. 80. Freire DMG, Castilho LR. Lipases em Biocatálise. In: Bon EPS, Ferrara MA, Corvo ML, Vermelho AB, Paiva CLA, Alencastro RB, et al., editors. Enzimas em Biotecnologia - Produção, Aplicações e Mercado. Rio de Janeiro: Interciência; 2008.

81. Madigan MT, Martinko JM, Stahl D, Clark DP. Brock Biology of Microorganisms. 13th ed. San Francisco: Benjamin Cummings; 2012.

82. Borzani W, Schmidell W, Lima UA, Aquarone E. Biotecnologia Industrial. Vol. 1. Fundamentos. São Paulo: Blucher; 2001.

83. Mota M, Lima N. Biotecnologia: Fundamentos e Aplicações. Lisboa; 2003. 